Article

\title{
Estimation of Suspended Matter, Organic Carbon, and Chlorophyll-a Concentrations from Particle Size and Refractive Index Distributions
}

\author{
Jacopo Agagliate ${ }^{1, * \mathbb{D}}$, Rüdiger Röttgers ${ }^{2}$, Kerstin Heymann ${ }^{2}$ and David McKee ${ }^{1}$ \\ 1 Department of Physics, University of Strathclyde, 107 Rottenrow, Glasgow G4 ONG, UK; \\ david.mckee@strath.ac.uk \\ 2 Helmholtz-Zentrum Geesthacht, Max-Planck-Straße 1, 21502 Geesthacht, Germany; \\ rroettgers@hzg.de (R.R.); kerstin.heymann@hzg.de (K.H.) \\ * Correspondence: jacopo.agagliate@strath.ac.uk
}

Received: 1 February 2018; Accepted: 23 July 2018; Published: 19 December 2018

\begin{abstract}
Models of particle density and of organic carbon and chlorophyll-a intraparticle concentration were applied to particle size distributions and particle real refractive index distributions determined from flow cytometry measurements of natural seawater samples from a range of UK coastal waters. The models allowed for the estimation of suspended particulate matter, organic suspended matter, inorganic suspended matter, particulate organic carbon, and chlorophyll-a concentrations. These were then compared with independent measurements of each of these parameters. Particle density models were initially applied to a simple spherical model of particle volume, but generally overestimated independently measured values, sometimes by over two orders of magnitude. However, when the same density models were applied to a fractal model of particle volume, successful agreement was reached for suspended particulate matter and both inorganic and organic suspended matter values (RMS\%E: $57.4 \%, 148.5 \%$, and $83.1 \%$ respectively). Non-linear organic carbon and chlorophyll-a volume scaling models were also applied to a spherical model of particle volume, and after an optimization procedure achieved successful agreement with independent measurements of particulate organic carbon and chlorophyll-a concentrations (RMS\%E: $45.6 \%$ and 51.8\% respectively). Refractive index-based models of carbon and chlorophyll-a intraparticle concentration were similarly tested, and were also found to require a fractal model of particle volume to achieve successful agreement with independent measurements, producing RMS $\% \mathrm{E}$ values of $50.2 \%$ and $45.2 \%$ respectively after an optimization procedure. It is further shown that the non-linear exponents of the volume scaling models are mathematically equivalent to the fractal dimensionality coefficients that link cell volume to mass concentration, reflecting the impact of non-uniform distribution of intracellular carbon within cells. Fractal models of particle volume are thus found to be essential to successful closure between results provided by models of particle mass, intraparticle carbon and chlorophyll content, and bulk measurements of suspended mass and total particulate carbon and chlorophyll when natural mixed particle populations are concerned. The results also further confirm the value of determining both size and refractive index distributions of natural particle populations using flow cytometry.
\end{abstract}

Keywords: forward modeling; suspended matter; marine particles; fractal structure; organic carbon; chlorophyll-a

\section{Introduction}

The determination of suspended particulate mass concentrations (minerogenic mass, biomass, chlorophyll content) in marine particle populations is a matter of particular interest to ocean sciences, 
and one of the key aspects of the characterization of the properties of marine particles. The relationship between particulate mass properties and optical properties of seawater is important for understanding the formation of optical remote sensing signals and their interpretation.

In previous work carried out on a set of seawater samples collected in UK coastal waters (UKCW dataset), a Mie-based flow cytometric method (FC method) was developed to determine particle size distributions (PSDs) and real refractive index distributions (PRIDs), and its results used as inputs for Mie theory forward modelling to reconstruct not only bulk inherent optical properties (IOPs), but also individual fractions and optical contributions from inorganic, organic, and fluorescent particle subpopulations [1,2]. Although flow cytometric determination of particle physical properties and the subsequent modelling of IOPs have some precedent [3-5], no true effort has been devoted to extending the procedure to the reconstruction of particulate mass concentrations from flow cytometric data. Indeed, coupled with models of particle density and carbon intraparticle concentration, particle size, and real refractive index distributions offer the chance to explore the biogeochemical properties of a particle population from a new perspective.

In this study, models of organic and inorganic particle density are adapted from literature and applied to the UKCW dataset to produce modelled values of suspended particulate matter (SPM), organic suspended matter (OSM), and inorganic suspended matter (ISM). Furthermore, cell volume scaling models and refractive index-based models are also adapted from literature to allow estimation of intraparticle carbon $\left(C_{i}\right)$ and intraparticle chlorophyll-a $\left(C h l_{i}\right)$ content, ultimately producing modelled values of particulate organic carbon (POC) and chlorophyll-a concentrations (ChlA) from the particle data of the UKCW dataset. The modelled values thus obtained are then compared against the results of actual biogeochemical measurements, and the parameters used to assess carbon and chlorophyll concentrations are optimized on a dataset-wide basis to explore the physiology of the cells encountered during the He442 research cruise. A summary of the abbreviations and notations used throughout the study is given in Table 1.

Table 1. Abbreviations and notations used in this study.

\begin{tabular}{|c|c|}
\hline Notation & Definition \\
\hline ChlA & Chlorophyll-a concentration, $\mathrm{mg} \mathrm{m}^{-3}$ \\
\hline FC & Flow cytometer; flow cytometry \\
\hline IOP & Inherent optical property \\
\hline ISM & Inorganic suspended matter, $\mathrm{g} \mathrm{m}^{-3}$ \\
\hline OSM & Organic suspended matter, $\mathrm{g} \mathrm{m}^{-3}$ \\
\hline SPM & Suspended particulate matter, $\mathrm{g} \mathrm{m}^{-3}$ \\
\hline POC & Particulate organic carbon, $\mathrm{mg} \mathrm{m}^{-3}$ \\
\hline PRID & Particle real refractive index distribution \\
\hline PSD & Particle size distribution \\
\hline $\mathrm{RMS} \% \mathrm{E}$ & Root-mean-square percentage error \\
\hline RMSE & Root-mean-square error \\
\hline UKCW & UK coastal waters (dataset) \\
\hline$a, a_{C}, a_{c h l}$ & $\begin{array}{l}\text { Slopes of the refractive index-based models and of the of the } C_{i} \text { and } C h l_{i} \text { optimized } \\
\text { refractive index-based models respectively, } \mathrm{kg} \mathrm{m}^{-3}\end{array}$ \\
\hline$b$ & $y$-intercepts of the refractive index-based models, $\mathrm{kg} \mathrm{m}^{-3}$ \\
\hline$F(r)$ & Fractal dimension, dimensionless \\
\hline$h_{1}, h_{2}$ & $\begin{array}{l}\text { Power law exponents of the optimized POC and ChlA volume scaling functions } \\
\text { respectively, dimensionless }\end{array}$ \\
\hline$k$ & Particle size distribution scaling coefficient, $\mathrm{mL}^{-1}$ \\
\hline$k_{1}, k_{2}$ & $\begin{array}{l}\text { Scaling coefficients of the optimized POC and ChlA volume scaling functions respectively, } \\
\text { pg } \mu \mathrm{m}^{-3}\end{array}$ \\
\hline$m_{\text {tot }}$ & Total particle mass, $\mathrm{mg}$ \\
\hline$C_{i}$ & Intraparticle carbon concentration, $\mathrm{kg} \mathrm{m}^{-3}$ \\
\hline $\mathrm{Chl}_{i}$ & Intraparticle chlorophyll-a concentration, $\mathrm{kg} \mathrm{m}^{-3}$ \\
\hline
\end{tabular}


Table 1. Cont.

\begin{tabular}{|c|c|}
\hline Notation & Definition \\
\hline$N(D)$ & $\begin{array}{l}\text { Number concentration of particles within particle size bin corresponding to particle } \\
\text { diameter } \mathrm{D}, \mathrm{mL}^{-1}\end{array}$ \\
\hline$N^{\prime}(D)$ & Density function of the particle size distribution, $\mathrm{mL}^{-1} \mu \mathrm{m}^{-1}$ \\
\hline$N_{r}$ & $\begin{array}{l}\text { Number of particles within particle size bin corresponding to particle radius } r \text {, } \\
\text { dimensionless }\end{array}$ \\
\hline$N_{D, n r}$ & $\begin{array}{l}\text { Number of particles within particle bin corresponding to particle diameter } D \text { and real } \\
\text { refractive index } n_{r} \text {, dimensionless }\end{array}$ \\
\hline$n_{0}$ & Real refractive index of the dry matter fraction of the particle, dimensionless \\
\hline$n_{r}$ & Real refractive index of the particle, dimensionless \\
\hline$n_{i}$ & Imaginary refractive index of the particle, dimensionless \\
\hline $\bar{n}_{r, 1}, \bar{n}_{r, 2}$ & $\begin{array}{l}\text { Average real refractive indices at the upper and lower extremes of the particle size } \\
\text { distribution respectively, dimensionless }\end{array}$ \\
\hline$r, D$ & Particle radius and particle diameter, $\mu \mathrm{m}$ \\
\hline$r_{0}$ & Primary particle radius, $\mu \mathrm{m}$ \\
\hline$V_{D}$ & Particle volume, $\mu \mathrm{m}^{3}$ \\
\hline$V_{o}$ & Volume of the dry matter fraction of the particle, $\mu \mathrm{m}^{3}$ \\
\hline$y(r)$ & Volume scaling function \\
\hline$B$ & Fractal dimension exponent, dimensionless \\
\hline$\gamma$ & Power law slope, dimensionless \\
\hline$P$ & Particle density, $\mathrm{g} / \mathrm{m}^{3}$ \\
\hline$\rho_{n r}$ & Density of a particle with real refractive index $n_{r}, \mathrm{~g} / \mathrm{m}^{3}$ \\
\hline$\rho_{0}$ & Density of the dry matter fraction of the particle, $\mathrm{g} / \mathrm{m}^{3}$ \\
\hline
\end{tabular}

\section{Materials and Methods}

\subsection{Theory}

\subsubsection{Particle Mass Modelling from Apparent Density of Hydrated Matter}

Calculations for modelled values of SPM, OSM, and ISM were made following the technique presented by Zhang et al. [6]. Building on the approach presented by Morel \& Ahn [7] and Babin et al. [8] the technique estimates a density value for the particulate matter which is dependent on the real part of the refractive index of the particles and is designed to account for their water content. Since this value is neither the value of the dry matter fraction of the particle nor that of water, but rather a combination of the two, this global density is also known as "apparent" density. The equation takes the form

$$
\rho=\rho_{o} V_{o}=\rho_{o} \frac{n_{r}-1}{n_{o}-1}
$$

where $n_{r}$ is the real refractive index of the whole particle and $n_{0}, \rho_{0}$, and $V_{o}$ are respectively the real refractive index, density, and fractional volume of the dry matter fraction of the particle. All refractive index values are given relative to water.

Values for the $\rho_{o} /\left(n_{0}-1\right)$ ratio were defined following those employed by Zhang et al. [6]. For organic particles (defined as the fraction of the particle population with $n_{r}<1.1$ ) the mean value of the ratio was set at $(8.56 \pm 1.1) \times 10^{6} \mathrm{~g} / \mathrm{m}^{3}$. These are particles with high water content, as high as $\sim 80 \pm 10 \%$ for algal cells [9]. For mineral particles (defined as the fraction of the particle population with $\left.n_{r} \geq 1.1\right)$ the mean value of the ratio was instead set at $(15.52 \pm 1.84) \times 10^{6} \mathrm{~g} / \mathrm{m}^{3}$. These particles have low water content; when the fractional volume of dry matter reaches unity (i.e., water content within the particles is zero) the apparent density of the particle becomes equal to the density of the dry mineral matter and can be calculated accordingly. Zhang et al. [6] find $n_{r}=1.16$ as the threshold above which $V_{o}=1$, and give $\rho=\left[(6.42 \pm 0.85) n_{r}-(4.86 \pm 0.99)\right] \times 10^{6} \mathrm{~g} / \mathrm{m}^{3}$ as the corresponding 
density based on a linear regression of literature values of density and refractive index for a number of mineral species. Overall, the final expression of Equation (1) used in practice was

$$
\rho=\left\{\begin{array}{cc}
8.56 \times 10^{6}\left(n_{r}-1\right) & n_{r}<1.1 \\
15.52 \times 10^{6}\left(n_{r}-1\right) & 1.1 \leq n_{r}<1.16 \\
6.42 \times 10^{6} n_{r}-4.86 \times 10^{6} & n_{r} \geq 1.16
\end{array}\right.
$$

with all density values given as $\mathrm{g} / \mathrm{m}^{3}$.

\subsubsection{Particulate Organic Carbon and Chlorophyll-a Cell Volume Scaling}

Organic carbon and chlorophyll-a concentrations within a cell are not linear functions of the cell volume (also defined as biovolume by some authors); $C_{i}$ and $C h l_{i}$ values can be instead derived using empirical relationships defined by volume scaling exponents, which can be then summed over organic and fluorescent PSDs to obtain POC and ChlA values respectively, i.e.,

$$
C=\sum_{r} y(r) N_{r}
$$

where $C$ represents either POC or ChlA, $y(r)$ is the corresponding size-dependent total carbon or chlorophyll concentration per cell and $N_{r}$ is the number of particles within each size bin. A number of these empirical conversion relationships can be found in the literature for the modelling described here: four sets of parameters for carbon [10-12] and two sets of parameters for chlorophyll-a [11,13] were employed. These are presented in Table 2.

Table 2. Particulate organic carbon and chlorophyll-a cell volume scaling models used in this study

\begin{tabular}{cc}
\hline \multicolumn{2}{c}{ POC \& ChlA Cell Volume Scaling } \\
\hline Particulate Organic Carbon & Source \\
\hline$y(r)=0.433 V(r)^{0.863}$ & {$[10]$} \\
$y(r)=0.109 V(r)^{0.991}$ & {$[11]$} \\
$y(r)=0.288 V(r)^{0.811}$ & {$[12]$ (diatoms) } \\
$y(r)=0.216 V(r)^{0.939}$ & {$[12]$ (non-diatom mixed protists) } \\
\hline Chlorophyll-a & Source \\
\hline$y(r)=0.00429 V(r)^{0.917}$ & {$[11]$} \\
$y(r)=0.0398 V(r)^{0.863}$ & {$[13]$} \\
\hline
\end{tabular}

\subsubsection{Refractive Index-Based Estimation of Particulate Organic Carbon and Chlorophyll-a}

Research carried out in the 1990s demonstrated that cell volume is not the only parameter that can be used to estimate $C_{i}$ and $C h l_{i}$ values. In a series of studies [14-18], a number of empirical relationships were established for various phytoplankton species between the real refractive index $n_{r}$ and $C_{i}$ and between the imaginary refractive index $\left(n_{i}\right)$ and $C h l_{i}$. Expanding on this premise, Stramski [19] established refractive index-based linear models for the estimation of $C_{i}$ and $C h l_{i}$ based on data from two phytoplankton species

$$
\begin{gathered}
C_{i}=3441.055 n_{r}(660 \mathrm{~nm})-3404.99 \\
C h l_{i}=996.86 n_{i}(675 \mathrm{~nm})+1.17 .
\end{gathered}
$$

A follow-up work by DuRand et al. [20] established slightly modified relationships with the inclusion of data from additional phytoplankton species

$$
C_{i}=3946 n_{r}(650 \mathrm{~nm})-3922
$$




$$
\mathrm{Chl}_{i}=1244 n_{i}(675 \mathrm{~nm})-0.32 .
$$

These can then be associated with a particle volume model and with particle sizes as provided by PSDs to determine POC and ChlA values. Both sets of equations were employed in this work. The $n_{r}$ values contained in the PRIDs were originally determined by the FC method for $\lambda=488 \mathrm{~nm}$, i.e., the wavelength of the laser source used within the flow cytometer [1]; however, $n_{r}$ values are only weakly dependent on the wavelength (e.g., [21]), and Equations (4) and (6) are thus likely to be usable as is for the UKCW PRIDs as well. The FC method does not provide any information on the $n_{i}$ values; as will be described in Section 2.2.4, these were derived from literature. The relevant $n_{i}$ value (i.e., for organic particles at $\lambda=675 \mathrm{~nm}$ ) was adapted from Babin et al. [8] as $n_{i}=1.620 \times 10^{-3}$.

\subsection{Methods}

The particle density, carbon and chlorophyll cell volume scaling, and $C_{i}$ and $C h l_{i}$ refractive-index based estimation models were applied to the PSDs and PRIDs of the UKCW dataset as determined by the FC method, which can be found described in detail in [1]. A description of the dataset and of the measurement protocols (particularly those relative to SPM, ISM, OSM, POC, and ChlA measurements) is summarised below. Resulting mass concentrations obtained by modelling from FC data were then compared with corresponding suspended matter, organic carbon, and chlorophyll concentration values determined from traditional sample analysis. Cumulative contributions from different size classes were also calculated for SPM, ISM, OSM, and POC.

\subsubsection{UK Coastal Waters (UKCW) Dataset}

The UKCW dataset consists of natural water samples obtained during the He442 research cruise in UK waters (4-21 April 2015) on board the R/V Heincke (Alfred-Wegener-Institute, Bremerhaven, Germany). Sixty-two stations were sampled across a variety of optical water conditions around the coast of the UK (Figure 1), supplying a total of 50 samples with complete sets of FC data and matching data from other instruments and independent measurements. This included SPM, ISM, OSM, POC, and ChlA values obtained from lab analysis of the water samples retrieved during the research cruise. Wind conditions were favourable throughout, ranging from calm to moderate gale, and did not hamper the measurement process at any point during the cruise. Day-to-day weather ranged widely from clear sky conditions to heavy rain, although good weather was generally prevalent. Of particular note was the very high particle load found in Bristol Channel waters, which resulted in particularly large values of SPM, ISM, and OSM, as will be described in the following.

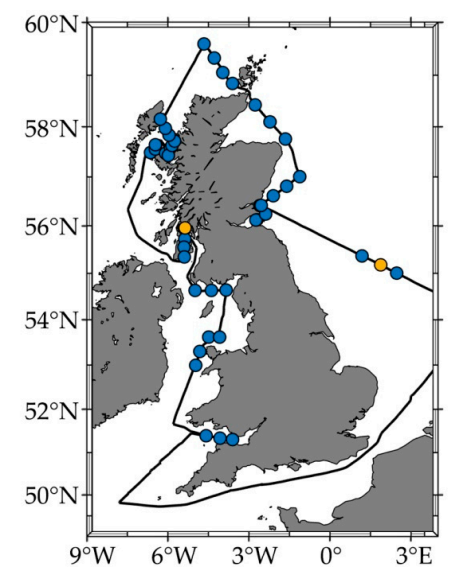

Figure 1. Track of the He442 research cruise, which took place in April 2015 in UK coastal waters aboard R/V Heincke. Out of the 62 measurement stations visited a total of 50 complete sets of data were retrieved, matching flow cytometric data, and ancillary measurements (blue circles). Yellow circles denote stations where two samples were taken. The figure was adapted and modified with permission from Figure 1 of Agagliate et al. [2]. 


\subsubsection{Depth Profiling}

Main depth profiling was done via an instrument frame equipped with Niskin bottles for sample retrieval. The frame was lowered through the water column at each of the stations, kept at a maximum depth for a first round of sampling, then raised to near surface depth to retrieve further samples. The samples were taken from the Niskin bottles on the frame as quickly as possible after the frame was back on deck and filled into 10-L plastic containers. In waters with high turbidity the Niskin bottles were flushed twice to avoid settling out of particulate matter. Forty-eight out of the 50 samples of the UKCW dataset are surface samples (depth: 5-7 m), with further two samples taken from bottom depths instead. The prevalence of surface samples within the dataset is due to the focus of the cruise, which was on developing data sets in support of the Sentinel remote sensing missions.

\subsubsection{Flow Cytometry Measurement Protocol}

All samples were measured by a CytoSense flow cytometer (CytoBuoy b.v., Woerden, The Netherlands) once for each of four sensitivity settings of the side scattering photomultiplier tube $(50,60,70,80)$, for $6 \mathrm{~min}$ and at a flow rate of $0.5 \mu \mathrm{L} / \mathrm{s}$. Side scattering was used as the trigger channel in all cases. The reader is directed to [1] for a detailed description of the CytoSense flow cytometer and its operation, particularly in the context of the UKCW dataset. Additional measurements of standard polymer beads necessary for calibration of the FC method were taken daily across the whole sampling period. A detailed description of the FC method and of the procedure followed to reconstruct PSDs and PRIDs can also be found in [1], where the application of the method to the UKCW dataset is also discussed specifically.

\subsubsection{PSD Extrapolations}

The mass concentration modelling will require the entire optically relevant particle distribution to be included as the input, or the output will not be comparable with independently measured mass concentration values. The FC method was found to reliably retrieve particle diameters between $\sim 0.5-10 \mu \mathrm{m}$ [1]. This range covers a large fraction of the contribution to scattering and backscattering, but the whole optically relevant range spans from tens of nanometers to a few millimeters [22,23]. The undetectable fraction of the particle population has to be accounted for using an approximation of the PSD to extend the range of the distribution over the whole relevant range.

Ever since pioneering work in the '60s and '70s found that the number of particles suspended in the ocean increased continuously and monotonically towards smaller scales [24,25], power law distributions of the type used by Junge [26] for aerosols have been the most common form of approximation for natural seawater particle populations [27,28]. The PSDs determined by the FC method for the UKCW dataset broadly conformed to this model, and consequently, following in the steps of Green et al. [5], a least squares best fit of the UKCW PSDs through power law distributions as defined by

$$
N(D)=N^{\prime}(D) d D=k D^{-\gamma} d D
$$

was used to extend the range of the measured PSDs (Figure 2). Here $N(D)$ is the number concentration of particles within the size bin corresponding to diameter $D, N^{\prime}(D)$ the density function of the PSD, $d D$ the width of the size bin, $k$ the scaling coefficient of the PSD, and $\gamma$ its slope. The form given in Equation (8) is necessary because the FC PSDs have bin-like nature; accordingly, the extrapolations need to be bin-like as well.

Values for the real refractive index $n_{r}$ in the Junge extensions must also be accounted for using some approximation of the PRID to extend the range of known refractive indices; this was done by averaging $n_{r}$ at the extremes of the measured PSD fraction (last four bins on either side) and using these averaged values on the respective arms of the extension (Figure 2). Since the FC method does not offer any information on the imaginary part of the refractive indices, $n_{i}$ values are unknown both in the available FC PSDs and in their extrapolations. Typical values for $n_{i}$ were therefore adapted 
from literature (Figure 8 of Babin et al. [8]), for both organic and inorganic particles. These were then assigned to the particles according to the value of the real refractive index of each bin, both directly determined by the FC method and extrapolated.

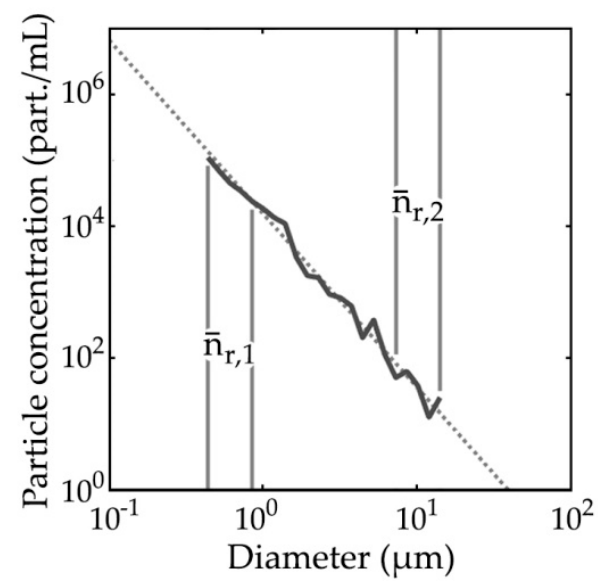

Figure 2. Power law best fit and real refractive index approximation in a typical natural particle population sample. Independent $n_{r}$ values obtained by averaging the $n_{r}$ of particles at the extremes of the PSD $\left(\bar{n}_{r, 1}, \bar{n}_{r, 2}\right)$ were used to approximate the real refractive index within the respective ends of the PSD extrapolation (dotted line). The figure was adapted and modified with permission from Figure 3 of Agagliate et al. [2].

\subsubsection{Suspended Particulate Matter and Inorganic/Organic Suspended Matter}

Suspended particulate matter (SPM) was obtained from each sample following procedures detailed by Röttgers et al. [29]. The sample was filtered through filter pads under low vacuum (47-mm Whatman GF/F glass-fiber filters), then immediately placed in a petri dish after filtration and put to dry in a vacuum desiccator: SPM values were subsequently obtained by weighing the mass of dried sample and dividing it by the sample volume used. SPM values ranged between 45.519 and $0.113 \mathrm{~g} / \mathrm{m}^{3}$, with highest values found in the Bristol Channel and lowest values found in the North Sea, although variance in this latter area was large. Further separation into organic suspended matter and inorganic suspended matter fractions (OSM and ISM, also found in literature respectively as particulate organic matter and particulate inorganic matter, POM and PIM) was obtained by volatization of organics at $500{ }^{\circ} \mathrm{C}$. ISM values ranged between 38.373 and $0.038 \mathrm{~g} / \mathrm{m}^{3}$, and followed a geographic pattern similar to that of SPM. OSM values ranged between 4.487 and $0.053 \mathrm{~g} / \mathrm{m}^{3}$, and were found to be more evenly distributed across the cruise track. The lowest value was found in the Irish Sea, while the highest was found once again in the Bristol Channel, due to the very large particle load of its turbid waters.

\subsubsection{Particulate Organic Carbon}

Particulate organic carbon (POC) concentrations were determined by catalytic combustion using a Vario TOC Cube instrument (Elementar, Langenselbold, Germany). Between 0.5 and $1 \mathrm{~L}$ of collected water for each sample were initially filtered onto $25-\mathrm{mm}$, combusted Whatman GF/F glass-fiber filters. The filters were then frozen and transported to the home laboratory. Once there, the filters were dried at $55{ }^{\circ} \mathrm{C}$, packed into tin capsules and analyzed for their carbon content. Separation or removal of inorganic carbon was not considered, as concentrations of inorganic carbon (calcite or carbonates) are assumed low for these waters. Calibration of the POC/TOC analyzer was done regularly using sulphanilamide as the calibration standard. POC values were found to range between $2.307 \times 10^{3}$ and $6.783 \times 10^{1} \mathrm{mg} / \mathrm{m}^{3}$, and followed a geographic pattern similar to that of OSM. Lowest values were found around Skye and the Hebrides, and highest values in the Bristol Channel. 


\subsubsection{Chlorophyll-a}

Chlorophyll-a concentration (ChlA) was determined using high-performance liquid chromatography (HPLC) following Zapata et al. [30]: specifically, ChlA was determined from fluorescence values using excitation at $440 \mathrm{~nm}$ and emission at $650 \mathrm{~nm}$ and by comparison with standards of known chlorophyll concentration. ChlA values ranged between 7.620 and $0.096 \mathrm{mg} / \mathrm{m}^{3}$, with lowest values found in the Firth of Clyde and highest values found in the North Sea.

\section{Results}

\subsection{PSDs and PRIDs}

The PSDs retrieved by the FC method for the UKCW dataset were found to broadly follow power law distributions, with the main difference between stations being the overall concentration of the particle population (Figure 3a). Two obvious outliers are present, corresponding to samples from the turbid waters of the Bristol Channel; close inspection reveals structures that may be closer in nature to models such as the double gamma distribution proposed by Risović [31], and that indeed may be identified to a lesser degree in the other samples as well. Nonetheless, the power law approach remains a reasonable approximation for a large majority of the dataset, and was used for PSD extrapolations accordingly for all samples including the Bristol Channel ones.
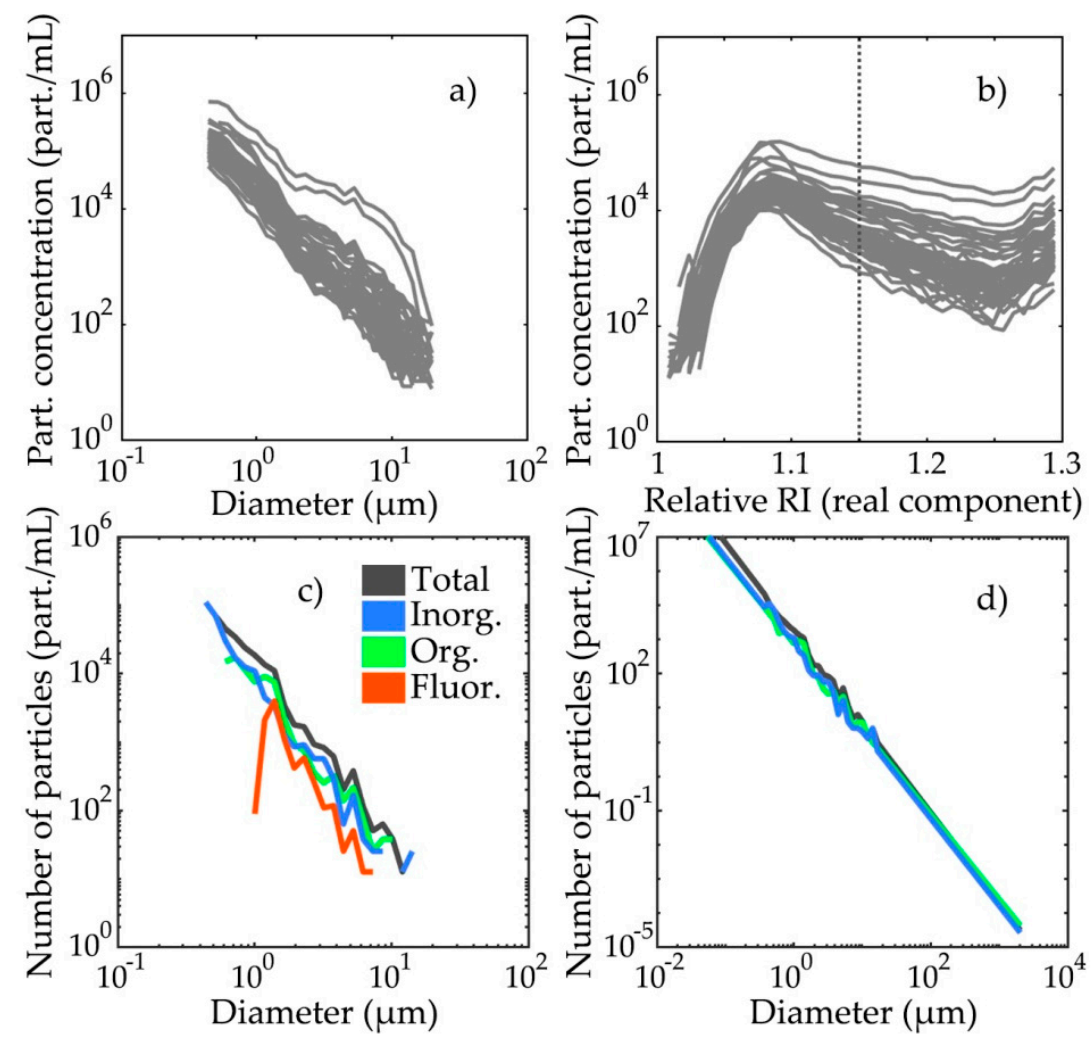

Figure 3. Collective view of (a) all 50 UKCW PSDs and (b) UKCW PRIDs produced by the FC method. Note that real refractive index values above 1.15 are not precise, but still indicate high refractive indices [1]. (c) Total, organic, inorganic, and fluorescent PSDs for a typical sample of the UKCW dataset and (d) power law extension of the total, organic and inorganic PSDs. Note that the extended organic and inorganic PSDs intersect the extended total PSD; therefore the sum of the extended organic and inorganic PSDs is not exactly equal to the extended total SPM. To evaluate the error thus introduced, SPM values are modelled both from the total PSD and by summing model ISM and OSM values. Panels $(\mathbf{a}, \mathbf{b})$ of the figure were adapted and modified with permission from Figure 2 of Agagliate et al. [2]. 
Particle refractive index distributions were found to be fairly homogeneous across all samples (Figure 3b), with distribution peaks found between 1.05-1.15 and within expectations for the real refractive index of the most common components of marine particle populations [9,32]. By exploiting the particle composition information given by the PRIDs, the total PSD of each UKCW sample was further separated into an inorganic PSD, an organic PSD, and a fluorescent fraction, which is itself a sub-fraction of the organic PSD (Figure 3c). These were used to calculate ISM, OSM \& POC, and ChlA respectively, while SPM was calculated both from the total PSD and as the sum of the model ISM and OSM. To account for the fraction of the particle population undetected by the FC method, the total organic and inorganic PSDs were extended between 0.05 and $2000 \mu \mathrm{m}$ as suggested by Davies et al. [23], following Equation (8) (Figure 3d); note that since the PSD extrapolations only approximate the particle populations outside the FC method detection range, the sum of the extended organic and inorganic PSDs generally is not exactly equal to the extended total PSD, making the dual calculation of SPM both from total PSD and as the sum of model ISM and OSM values a useful check of the error so introduced.

\subsection{Particle Mass Modelling}

Keeping with the assumption of particle sphericity used in the Mie-based models employed by the FC method, a first attempt of total particle mass calculation for the total, organic and inorganic fractions of the particle population was made as a simple bin-by-bin summation of spherical masses, i.e.,

$$
m_{t o t}=\sum_{D, n r} \rho_{n r} V_{D} N_{D, n r}
$$

where $\rho_{n r}$ is the apparent density of a particle with real refractive index $n_{r}$ as defined in Equation (2), $V_{D}$ is the volume of a sphere of diameter $D, D$ and $n_{r}$ are the diameter and real refractive index corresponding to each bin, and $N_{D, n r}$ is the number concentration of particles within each bin. Given Equation (9) SPM, ISM, and OSM can then be obtained respectively by summing over the entire range of refractive indices or by limiting the summation to real refractive index values above or below the $n_{r}=1.1$ threshold. The model SPM, ISM, and OSM values produced using this simple particle volume model however grossly overestimated the corresponding UKCW measurements, in certain cases by over two orders of magnitude (Figure 4).

A second calculation attempt was therefore carried out using a slightly modified version of the particle volume and total mass model employed in Zhang et al. [6]. This model is designed to account for the fractal nature of some marine particles, which can exist as aggregates of smaller units rather than as individuals exclusively, and takes the form

$$
m_{t o t}=\sum_{r, n r} \frac{4 \pi}{3}\left(\frac{r}{r_{o}}\right)^{F(r)} r_{o}^{3} \rho_{n r} N_{r, n r}
$$

where

$$
F(r)=3\left(\frac{r}{r_{0}}\right)^{\beta}
$$

Here it is assumed that the flow cytometer has measured the radius $r$ of an aggregate particle, which is itself constructed from primary particles of radius $r_{0} . F(r)$ is known as the fractal dimension of the aggregate. The value of $r_{o}$ and of exponent $\beta$ are given as $0.5 \mu \mathrm{m}$ and -0.0533 respectively [33], and for $r<r_{o}$ the value of $F$ is fixed at 3 . Crucially, the implementation of the model used here substitutes summation for the original integration to reflect the nature of the FC PSDs, extends the original range of $0.25-1000 \mu \mathrm{m}$ to the $0.05-2000 \mu \mathrm{m}$ range suggested by Davies et al. [23] and implements the effective radius $r$ directly as half the particle diameter $D$ determined by the FC method (rather than as the geometric formulation $4 / 3 \times V / A$ used by Zhang et al. [6], where $A$ is the average projected area). This usage of Mie-derived parameters within a fractal model of mass highlights the dual nature of such 
modelling procedure: Mie theory is initially employed within the FC method to retrieve an optical size for the particles; the fractal model then reconciles this value with their physical size.

Over the extended size range the value of $F$ was found to vary between 3 (its maximum possible value) and 1.998. The SPM, ISM, and OSM values produced using this fractal procedure were found to model the corresponding UKCW measurements much better than those produced using the simple spherical model, with RMS\%E values $57.4 \%, 148.5 \%$, and $83.1 \%$ for SPM, ISM, and OSM respectively (Figure 5). SPM values obtained as the sum of ISM and OSM were found to be close to those derived from the total PSD (RMS\%E value 65.2\%), indicating that the error introduced by the PSD extension is small. The two Bristol Channel samples, which deviated most obviously from the power law PSD model, produced clear outliers on all three accounts and were not included in the analysis. Median cumulative distributions of SPM, ISM, and OSM were also produced, showing that in a majority of samples $90 \%$ of the contribution to all three parameters is from particles between 0.2 and $200 \mu \mathrm{m}$ (Figure 6).
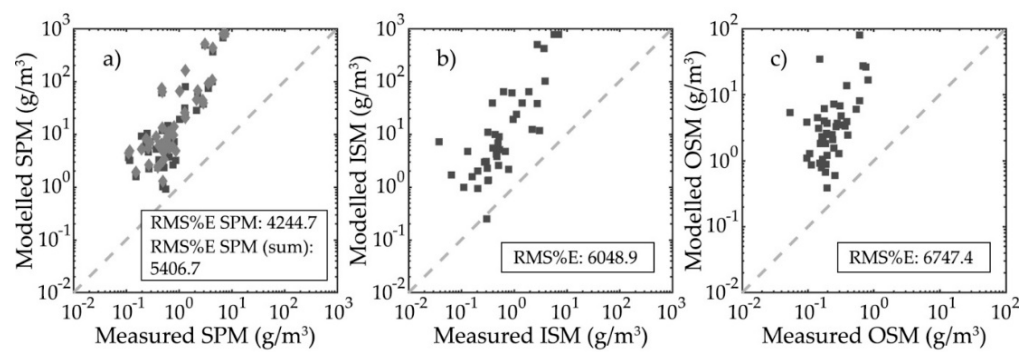

Figure 4. Comparison of modelled vs. measured (a) SPM, (b) ISM, and (c) OSM values for a simple spherical volume model. SPM values derived from the total PSD are represented as dark grey squares, while SPM values calculated as the sum of ISM and OSM are represented as light grey diamonds. The dashed grey lines indicate the 1:1 relationship.
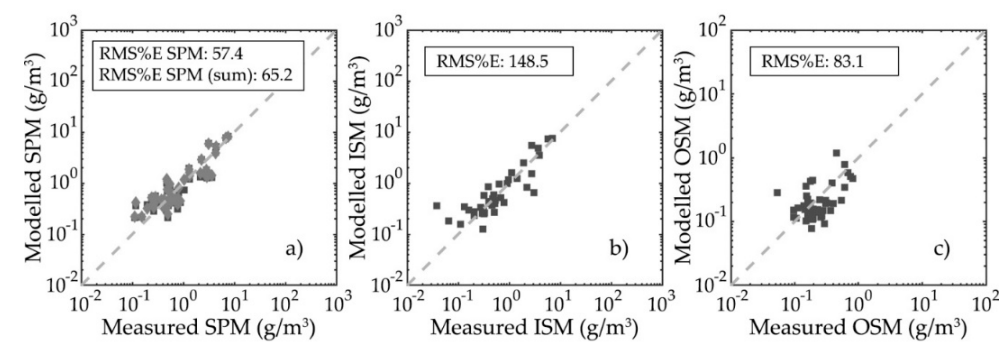

Figure 5. Comparison of modelled vs. measured (a) SPM, (b) ISM, and (c) OSM values for the fractal volume model. SPM values derived from the total PSD are represented as dark grey squares, while SPM values calculated as the sum of ISM and OSM are represented as light grey diamonds. The dashed grey lines indicate the 1:1 relationship.
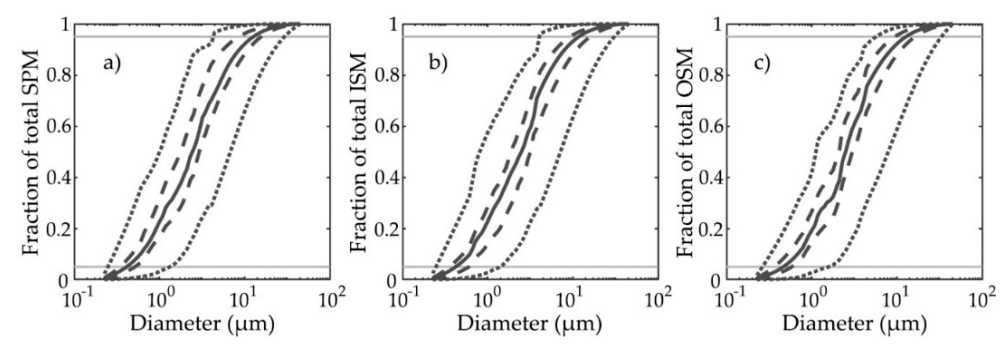

Figure 6. Cumulative distributions of modelled (a) SPM, (b) ISM, and (c) OSM values for the fractal volume model. The SPM curves refer to SPM values calculated from the total PSD. Solid, dashed, and dotted lines represent median, upper/lower quartiles, and maximum/minimum values respectively. The light grey horizontal lines mark the middle $90 \%$ of the contribution (i.e., from $5 \%$ to $95 \%$ ) to the total value of each parameter. 


\subsection{Particulate Organic Carbon and Chlorophyll-a Concentration Modelling}

For POC and ChlA modelling, the particle volume $V$ was once again defined using a simple spherical model. The first to be applied were the cell volume scaling models (Table 2). Of the four models used to calculate POC values, only the diatom model given by Menden-Deuer and Lessard [12] produced results compatible with POC measurements (RMS\%E: 92.9\%, Figure 7a). This possibly reflects the taxonomical composition of the algal populations encountered during the He442 research cruise being mainly composed of diatom species typically associated with the spring bloom. The median cumulative distribution of POC for the diatom model shows an almost linear contribution from all size classes in a majority of samples, although results are shown to range widely from cases where the contribution is dominated by small particles to cases where, oppositely, the largest particles contributed the most (Figure $7 \mathrm{~b}$ ). This is likely the result of the interaction between the model parameters and the slope of the PSDs, and may also indicate that the parameters of the model work well for a majority, but not all of the samples. The two chlorophyll-a models both produced unsatisfactory results, with one data set underestimating ChlA, and the other over-estimating ChlA (Figure 8). The RMS\%E values for the two sets were found to be $64.2 \%$ and $212.3 \%$ respectively. Although the overall quality of the match-up was low, the underlying structure of the data suggests that the form of the relationship might be useful subject to appropriate optimization.
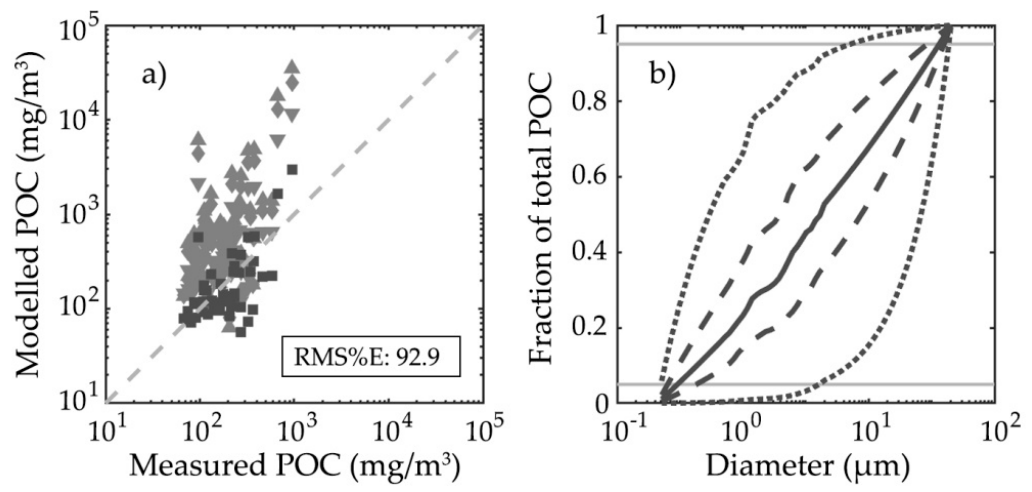

Figure 7. (a) Comparison of modelled vs. measured POC. POC values calculated using the diatom model (Menden-Deuer \& Lessard, 2000) are represented by dark grey squares; the RMS\%E value refers to these. POC values calculated using the other three models are represented by light grey diamonds and triangles; (b) Cumulative distribution of modelled POC for the diatom model. Solid, dashed, and dotted lines represent median, upper/lower quartiles, and max./min. values respectively. The light grey horizontal lines mark the middle $90 \%$ of the contribution (i.e., from $5 \%$ to $95 \%$ ) to the total POC value. The dashed grey line indicates the 1:1 relationship.

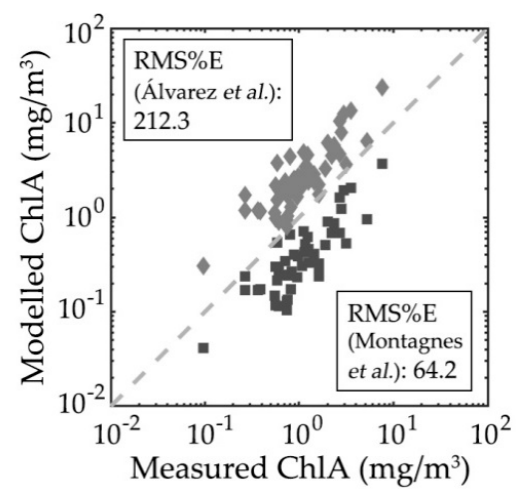

Figure 8. Comparison of modelled vs. measured ChlA. ChlA values calculated using the Montagnes et al. [11] model and the Álvarez et al. [13] model are represented by dark grey squares and light grey diamonds respectively. The dashed grey line indicates the 1:1 relationship. 
When the refractive index-based $C_{i}$ and $C h l_{i}$ estimation models (Equations (4)-(7)) were applied to POC and ChlA modelling, the comparison between modelled and measured values of POC produced results (Figure 9a) which echo those found for SPM, ISM, and OSM when simple spherical particle volumes are used (see Figure 4). As was the case for particle mass values, the model POC values grossly overestimated the corresponding UKCW measurements, in certain cases by over two orders of magnitude. In contrast, the comparison between modelled and measured values of ChlA (Figure 9b) produced results which are similar to those found with the Montagnes et al. [11] cell volume scaling model (see Figure 8): both the Stramski and the DuRand models i.e., Equations (5) and (7) underestimated the measured ChlA values, producing RMS\%E values of $63.3 \%$ and $76.5 \%$ respectively. Following the successful application of a fractal model of particle volume to the modelling of SPM, ISM, and OSM values, the same fractal model was applied to the refractive index-based $C_{i}$ and $C h l_{i}$ estimation as well by simple substitution of the $\rho$ term of Equation (10) with either $C_{i}$ or $C h l_{i}$. The POC values produced using the fractal procedure were found to model the corresponding UKCW measurements much better than those produced using the simple spherical model, with RMS\%E values of $51.4 \%$ and $49.2 \%$ for the Stramski [19] and Durand et al. [20] models respectively (Figure 9c). However, the modelled values of ChlA were driven to further underestimate the measured values by the adoption of fractal volumes. RMS\%E values for this new ChlA comparison were found to be $80.7 \%$ and $88.1 \%$ for the Stramski [19] and Durand et al. [20] models respectively (Figure 9d).
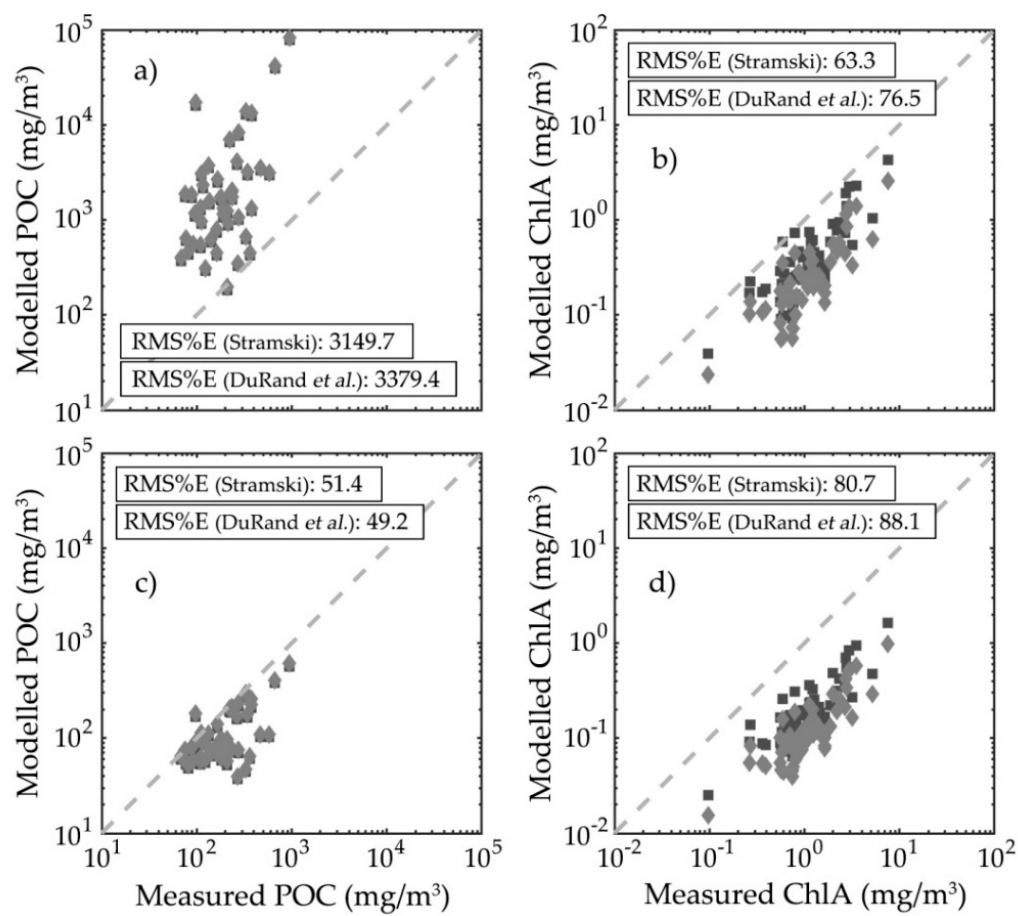

Figure 9. Comparison of (a) modelled vs. measured POC and (b) modelled vs. measured ChlA when a spherical model of particle volume is employed, and comparison of (c) modelled vs. measured POC and (d) modelled vs. measured ChlA when a fractal model of particle volume is employed instead. POC and ChlA values calculated using the Stramski [19] and Durand et al. [20] models are represented by dark grey squares and light grey diamonds respectively. The dashed grey lines indicate the $1: 1$ relationship.

\subsection{Particulate Organic Carbon and Chlorophyll-a Concentration Modelling Optimization}

A simple inversion of the procedure used to calculate POC and ChlA values allows for the empirical optimization of the parameter pairs used in the cell volume scaling models. Maintaining the general form

$$
y(r)=k V(r)^{h},
$$


arrays of values for the parameters $k$ and $h$ can be generated, combined, and substituted in Equation (12), and the results compared and fitted against available measurements to identify the best parameter combinations, respectively $\left(h_{1}, k_{1}\right)$ and $\left(h_{2}, k_{2}\right)$ for POC and chlorophyll-a intraparticle concentrations. The optimization was initially applied to the whole UKCW dataset. Three parameter arrays were generated, one shared by exponents $h_{1}$ and $h_{2}$ plus one each for factors $k_{1}$ and $k_{2}$. The ranges were designed to encompass the parameter values of the models used thus far: specifically, 201 linearly spaced values for exponents $h_{1}$ and $h_{2}$ in a 0.6-1 range, 301 linearly spaced values for factor $k_{1}$ in a 0.05-0.65 range and 461 linearly spaced values for factor $k_{2}$ in a 0.004-0.05 range. Each $\left(h_{1}, k_{1}\right)$ and $\left(h_{2}, k_{2}\right)$ combination was then applied dataset-wide, compared against measured POC and ChlA and evaluated using the goodness-of-fit of a forced linear fit of the 1:1 line. The best parameter combinations were selected as those that minimized the RMSE values of the forced fit. The best POC model for the UKCW dataset was found as

$$
y(r)=0.442 V(r)^{0.720}
$$

while the best chlorophyll-a model was found as

$$
y(r)=0.029 V(r)^{0.736} .
$$

Comparisons of the optimized model results with the measured POC and ChlA values of the UKCW dataset are shown in Figure 10. RMS\%E values for the comparisons were found to be $45.6 \%$ and $51.8 \%$ for POC and ChlA respectively.
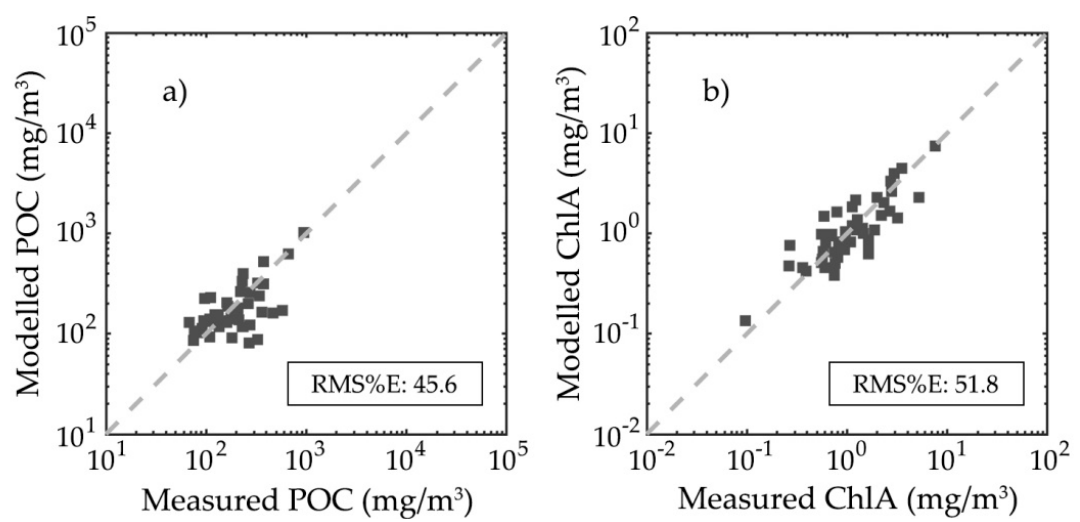

Figure 10. Comparison of (a) POC and (b) ChlA values as determined by the optimized models of Equations (13) and (14) vs. their respective measured values. The dashed grey lines indicate the 1:1 relationship.

An analogous optimization procedure can be applied to the refractive index-based $C_{i}$ and $C h l_{i}$ estimation models. Maintaining the use of fractal particle volumes and the general form

$$
C_{x}=a n_{x}-b
$$

common to both models as described by Equations (4)-(7), where $C_{x}$ is either $C_{i}$ or $C h l_{i}$ and $n_{x}$ is respectively either $n_{r}$ or $n_{i}$, arrays of values for the parameters $a$ and $b$ can be generated, combined and substituted in Equation (15), and the results compared and fitted against available measurements to identify the best parameter combinations. Interestingly, for both POC and ChlA the procedure could not identify single parameter combinations that minimized the RMSE; indeed, in both cases what was found was instead a continuum of parameter pairs which all minimized the RMSE to very similar values across the entire parameter ranges. We interpret this to be indicative of an excess of degrees of freedom in the relationship described by Equation (15) for the models to be properly constrained.

Returning to the physical basis of these relationships given in Stramski [19], the empirical linear relationship between $C_{i}$ and $n_{r}$ reflects a physical realization that increasing carbon content will 
generally increase real refractive index. Here we consider the implication of a natural boundary condition for this relationship: when $n_{r}=1$ then $C_{i}=0$. Including this constraint results in a slightly modified form of relationship

$$
C_{i}=a_{C}\left(n_{r}(660 \mathrm{~nm})-1\right)
$$

We note that this is equivalent to forcing the Stramski [19] regression (Figure 2 therein) through $\left(n_{r}, C_{i}\right)=(1,0)$. Given the experimental uncertainties noted in Stramski [19] and the similarity of the $a$ and $b$ components of the original regressions, we believe that the form proposed by Equation (16) is broadly comparable but better reflects the physical relationship under investigation. Similarly, in the case of $C h l_{i}$ and $n_{i}$ Stramski [19] provides a clear physical basis for a simple linear relationship based on earlier work by Morel and Bricaud [34]. A small offset is found in the resulting best-fit regressions, which is either small and positive (see Equation (5) here, Stramski [19]), or small and negative (see Equation (7) here, Durand et al. [20]). The initial model suggests that $n_{i}(675 \mathrm{~nm})$ ought to be a simple linear function of $C h l_{i}$, but in practice the small offset could represent residual absorption by pigments other than ChlA (Stramski [19]), or it could be a statistical artefact associated with limitations in data quality (the discrepancy in sign between the two aforementioned studies is possibly significant). In either case, a slightly modified version of the $n_{i}$ and $C h l_{i}$ relationship can be given as

$$
C h l_{i}=a_{\text {chl }} n_{i}(675 \mathrm{~nm})+\text { const } .
$$

However, it must be noted that the information contained in our data does not provide an indication of the appropriate value for the constant offset in Equation (17): indeed, the absence of a well-determined pair of best parameters when optimization is executed on both $a$ and $b$ terms of the linear model shows that minimal error for the dataset may be reached for any value of the offset. Therefore, the only likely way forward is to use the single well-defined scenario available i.e., the assumption of negligible residual absorption by pigments other than $\mathrm{Chl}_{i}$. Under this assumption, the constant offset equals zero.

Once applied to Equations (16) and (17), the optimization procedure thus defined identified minimal RMSE values for relationships

$$
\begin{gathered}
C_{i}=6880\left(n_{r}(660 \mathrm{~nm})-1\right) \\
C h l_{i}=8320 n_{i}(675 \mathrm{~nm}) .
\end{gathered}
$$

Comparisons of the optimized model results with the measured POC and ChlA values of the UKCW dataset are shown in Figure 11. RMS\%E values for the comparisons were found to be $50.2 \%$ and $45.2 \%$ for POC and ChlA respectively.
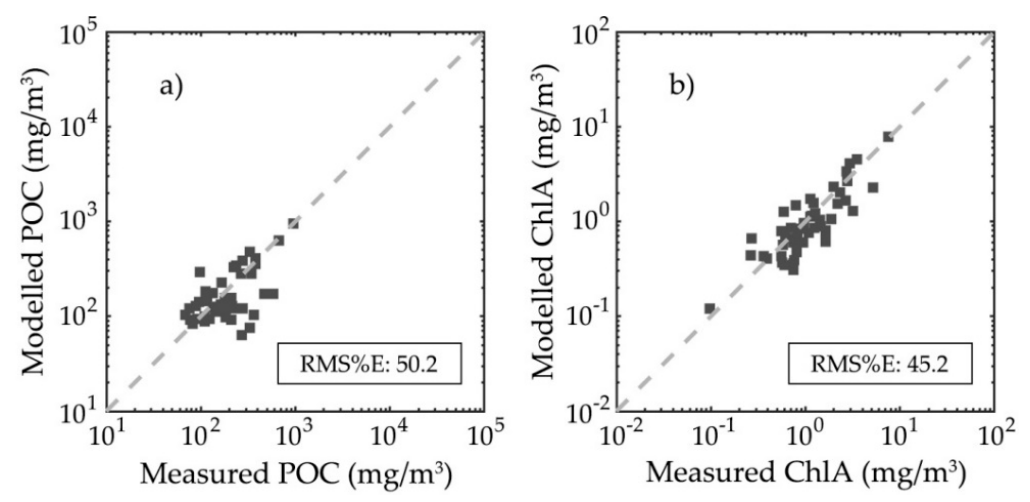

Figure 11. Comparison of (a) POC and (b) ChlA values as determined by the optimized models of Equations (17) and (18) vs. their respective measured values. The dashed grey lines indicate the 1:1 relationship. 


\section{Discussion}

The modelling of suspended matter parameters for the samples of the UKCW dataset produced an interesting result: PSDs and PRIDs generated using a sphere-based, Mie-derived methodology produced SPM, ISM, and OSM values which compared poorly with their corresponding measured parameters when paired with an equally simple spherical volume model (Figure 4). However, the same PSDs and PRIDs produced comparable results when used directly as inputs for a fractal model of particle volume instead (Figure 5). This reflects two important aspects that should be considered carefully. The first is that the particle diameters found by the FC method are equivalent diameters rather than a direct measure of the physical dimension of the particles strictly [2]. The second is that natural particle populations are not solid spheres, so it is necessary to consider the impact of volume scaling and shape effects on apparent densities. The fractal model effectively rescales apparent particle densities across the size range. This is a feature of dealing with polydisperse natural particle populations that may not be encountered when dealing with effectively monodisperse algal cultures.

Application of volume scaling models (Figures 7a and 8) was moderately successful in determining POC and ChlA concentrations, although the variable rate of success between models mirrors the lack of consensus on a single model to accurately represent size-physiology relationships in marine phytoplankton. Indeed, a single set of model parameters is likely to be insufficient to adequately represent the metabolic complexity of all algal organisms [35]. This seems to substantiate the concerns expressed by Stramski [19] in noting the large variability between results obtained using different cell volume scaling models. Nevertheless, the further application of an empirical optimization procedure produced good match-ups between modeled and measured POC and ChlA values across the UKCW dataset (Figure 10).

Refractive index-based models of $C_{i}$ and $C h l_{i}$ were found to require a fractal model of particle volume to produce modelled values comparable with measured ones, particularly in the case of POC (Figure 9). This mirrors the results found for the particle density models for SPM, ISM, and OSM, and suggests that fractal models of volume are necessary to reconcile linear formulations of particle density and intraparticle carbon content with corresponding bulk measurements when natural particle populations with a wide size range and complex composition are involved. The matter is less clear in the case of ChlA, for which the refractive index-based models underestimated measured values in the case of spherical volumes, and even more so in the case of fractal volumes. Since the particle volume model must be consistent between POC and ChlA, we interpret this not as an issue with the fractal approach but rather as a sign that other elements within the overall procedure may be problematic. For example, it is important to remember that the imaginary refractive indices used in the $C h l_{i}$ estimation represent an approximation based on a single $n_{i}$ value derived from the literature. A simple optimization procedure shows that the modelled ChlA values of Figure $9 b, d$ are reconciled with the corresponding measured values if $n_{i}(675 \mathrm{~nm})=12.3 \times 10^{-3}$ and $n_{i}(675 \mathrm{~nm})=11.1 \times 10^{-3}$ in the fractal volume case and if $n_{i}(675 \mathrm{~nm})=4.2 \times 10^{-3}$ and $n_{i}(675 \mathrm{~nm})=4.6 \times 10^{-3}$ in the spherical volume case (Stramski [19] and Durand et al. [20] models respectively in both cases). All four values are within the range shown in Table 1 of Stramski et al. [36], suggesting that a more dynamic range of $n_{i}$ values may in fact improve the agreement between measurements and prediction. Furthermore, the fluorescent PSDs used in the ChlA calculations are not always easily reconciled with a Junge-like size distribution, and thus cannot be extended beyond the FC functional size range in a straightforward manner (Figure 3c). This can easily lead to unobserved particle fractions (especially for particle sizes above $\sim 10 \mu \mathrm{m}$ ) and thus to underestimation of the actual total fluorescence.

This underestimation has a direct effect on the parameter values of the optimized refractive index-based models, which were found to be very large compared to those found in the literature (Equations (4)-(7), (18), and (19)). However, it should be noted that while the large value of the parameter $a_{c h l}$ can be explained by the issues mentioned above, the large value of the parameter $a_{C}$ may instead be explained by the very different context of the model's application. The original $C_{i}$ model was developed from the analysis of a small number of cultured phytoplankton species, which compared to 
the varied composition and extended size range of the He442 samples are essentially monotypic and probably log-normally distributed in their size. For both parameters, the good agreement obtained here (Figure 11) further confirms that fractal models of particle volume are appropriate and essential for successful closure between the results provided by linear formulations of biogeochemical parameters and their corresponding bulk measurements when natural mixed particle populations are concerned.

Given the results obtained for SPM, ISM, and OSM and for refractive index-derived values of POC and ChlA using a fractal model of particle volume, at a first glance the application of POC and ChlA volume scaling models to simple spherical volumes appears incongruous. However, close inspection of Equations (10)-(12) reveals that the POC and ChlA empirical volume scaling relationships hide proportionalities which are very close to those of the SPM, ISM, and OSM models. Specifically, from Equations (10) and (12) and for a single particle

$$
\begin{gathered}
m=r_{o}^{3-F(r)} \rho\left(\frac{4 \pi}{3}\right)^{1-\frac{F(r)}{3}}\left(\frac{4}{3} \pi r^{3}\right)^{\frac{F(r)}{3}}= \\
=u(r) V^{\frac{F(r)}{3}} \propto y=k V^{h} .
\end{gathered}
$$

Of particular interest then is the comparison between the exponents $h$ and $F(r) / 3$. Over the 0.05-2000 $\mu \mathrm{m}$ size range considered here, the value of $F(r)$ was found to vary between 3 and $\sim 2$, producing values of $F(r) / 3$ between 1 and 2/3. These not only cover the range of values of exponent $h$ in literature-derived and UKCW optimized volume scaling models for both POC and ChlA, but also echo general results found in literature for the volume scaling coefficients of chlorophyll and organic carbon. A physical interpretation of these results is that intracellular carbon is not uniformly distributed within cells, and this non-uniform distribution of intracellular carbon causes the observed non-linear relationship with cell volume. Based on the analysis above, we have found that the observed exponent in the cell volume model reflects the non-uniform distribution of carbon within the cell and can be used to predict the subsequent impact on the fractal dimensionality of the particle. As shown earlier in the paper, the fractal dimension of the particles controls the relationship between particle size distribution and observed mass concentrations (Figure 5).

Non-uniform distribution of intracellular carbon is also closely linked with cellular metabolism. Metabolic rate under optimal growth conditions is seen to scale with volume following a $3 / 4$ exponent for a large number of organisms in what is known as the 3/4 rule or Kleiber's rule [37], and in phytoplankton this relationship is directly tied to the photosynthetic rate, and ultimately to the intracellular chlorophyll-a concentration. In general, phytoplankton cells regulate their pigment concentration in response to environmental irradiance changes [37]. Values for the volume scaling coefficient are then variably predicted to range between $3 / 4$ and $2 / 3$ for optimal growth and light limited conditions respectively [37], or to reach $\sim 1$ when nutrients are abundant [35]. Álvarez et al. [13] report values between 3/4 and 1, and Mei et al. [38] modelled cellular growth rate scaling exponents using chlorophyll-a intraparticle concentration scaling exponents ranging between $2 / 3$ and 1 . Similarly, empirical estimates of the scaling between cell volume and particulate carbon also vary. Some authors find carbon intraparticle concentration to decrease proportionally with increasing cell size i.e., $h<1[10,12]$, while other find it to be isometric to cell size i.e., $h \sim 1$ [11].

Ultimately, the results presented in this study seem to suggest that, while cellular metabolic rate can be logically expected to play an important part in defining chlorophyll and organic carbon concentrations within organic particles, structural characteristics of the organic particles as described by fractal models can also offer a complementary interpretation for the proportionalities observed in nature and described in existing microbiology literature. This opens up interesting avenues for future research. For example, a simple attempt at repeating the optimization procedure for parameters $k_{1}$ and $k_{2}$ while substituting $F(r) / 3$ for volume scaling coefficient $h$ produced values $k_{1}=0.232$ for POC and $k_{2}=0.100$ for ChlA. The latter value is much larger than corresponding parameters found within the literature-derived ChlA volume scaling models employed in this work; furthermore, in both cases, modelled values of POC and ChlA resulted in a larger RMS\%E when compared with their 
respective measured values from the UKCW dataset, respectively $61.2 \%$ and $93.6 \%$ for POC and ChlA. This may suggest that the application of fractal volumes to organic carbon and chlorophyll-a concentrations determination via volume scaling models will require a different set of values for the primary radius $r_{O}$ and/or exponent $\beta$ compared to those used in the estimation of suspended matter concentrations. Coincidentally, this might also be further explanation for the underestimation found in modelled POC and especially ChlA values derived from refractive index based models of $C_{i}$ and $C h l_{i}$ when fractal volumes are applied. Most certainly, further in-depth research will be needed to answer these questions.

\section{Conclusions}

The results obtained by the FC method for the UKCW dataset were combined with models of particle density and of organic carbon and chlorophyll-a intraparticle concentrations to investigate the biogeochemical properties of the particle populations. The success of the resulting SPM, ISM, OSM and (after empirical optimization) POC and ChlA estimations lends further credibility to the PSD and PRID determination capabilities of the FC method, and further supports the usefulness of flow cytometry and of the FC method as a tool to complement other established techniques.

The fact that a fractal model of particle structure was key to ensure the quality of the SPM, ISM, OSM and refractive index-derived POC and ChlA match-ups suggests that the FC method observes particles as equivalent spheres, and has therefore the potential to be to some extent resilient both to particles which violate Mie-compatible aspect ratios and to the break-up of flocs and aggregates which derives from the flow cytometric measurement technique. Furthermore, this characteristic makes FC method results more readily comparable with those of other more common marine optics instruments, which for the most part observe bulk seawater IOPs and PSDs. It should be also noted that while the dataset was chiefly composed of surface water samples, no particular limitation exists a priori for the application of the FC method in its present form to samples from any water depth.

The volume scaling models used to calculate POC and ChlA were successfully applied to simple spherical particles instead. This may appear incongruous at first; however, these models too are revealed to hide proportionalities analogous to those caused by fractal structures, shining interesting new light on the volume scaling coefficients described in marine microbiology literature. We have shown here that the volume scaling models provide a route to better understand the impact of carbon distribution within particles and resulting fractal dimensionality, while the successful optimization of refractive index-based models reinforces previous findings that cell composition in the form of intracellular carbon concentration is well represented by corresponding changes in real refractive index. Finally, the size discrimination offered by FC also allows for a better understanding of the contribution of different size classes to the bulk biogeochemical properties, as it previously did for the IOPs of natural particle populations [2]. Taken in combination, these results represent a significant demonstration of the quality of size and refractive index information that is provided by FC data.

Author Contributions: J.A. and D.M. conceived and outlined the concept for this study; R.R. coordinated work during the HE442 research cruise; D.M. and R.R. supervised the retrieval of water samples; J.A. carried out flow cytometry operations; R.R. and K.H. carried out SPM, ISM, OSM, POC, and ChlA measurements on the water samples; J.A. analyzed the data; R.R. provided the Methods paragraphs relative to SPM, ISM, OSM, POC, and ChlA measurements; J.A. wrote the paper.

Funding: The HE442 cruise with RV Heincke was conducted under funding by the Alfred Wegener Institute Helmholtz Centre for Polar and Marine Research (AWI), grant AWI-HE442. This research was further funded by the Scottish Funding Council (SFC) (grant HR09011) via Marine Alliance for Science and Technology for Scotland (MASTS). This work was originally conceived thanks to work conducted under award of NERC grant $\mathrm{NE} / \mathrm{H} 021493 / 1$ to McKee and co-investigators.

Acknowledgments: Agagliate and McKee gratefully acknowledge financial support from the MASTS pooling initiative. The authors wish to thank the captain and the crew of RV Heincke for their support and help during the HE442 research cruise. The authors also duly thank D. Stramski and two anonymous reviewers, who all helped improve this manuscript with their comments and suggestions.

Conflicts of Interest: The authors declare no conflict of interest. 


\section{References}

1. Agagliate, J.; Röttgers, R.; Twardowski, M.S.; McKee, D. Evaluation of a flow cytometry method to determine size and real refractive index distributions in natural marine particle populations. Appl. Opt. 2018, 57, 1705-1716. [CrossRef] [PubMed]

2. Agagliate, J.; Lefering, I.; McKee, D. Forward modelling of inherent optical properties from flow cytometry estimates of particle size and refractive index. Appl. Opt. 2018, 57, 1777-1788. [CrossRef] [PubMed]

3. Ackleson, S.G.; Spinrad, R.W. Size and refractive index of individual marine particulates: A flow cytometric approach. Appl. Opt. 1988, 27, 1270-1277. [CrossRef] [PubMed]

4. Green, R.E.; Sosik, H.M.; Olson, R.J.; DuRand, M.D. Flow cytometric determination of size and complex refractive index for marine particles: Comparison with independent and bulk estimates. Appl. Opt. 2003, 42, 526-541. [CrossRef] [PubMed]

5. Green, R.E.; Sosik, H.M.; Olson, R.J. Contributions of phytoplankton and other particles to inherent optical properties in New England continental shelf waters. Limnol. Oceanogr. 2003, 48, 2377-2391. [CrossRef]

6. Zhang, X.; Stavn, R.H.; Falster, A.U.; Gray, D.; Gould, R.W., Jr. New insight into particulate mineral and organic matter in coastal ocean waters through optical inversion. Estuar. Coast. Shelf Sci. 2014, 149, 1-12. [CrossRef]

7. Morel, A.; Ahn, Y.-H. Optical efficiency factors of free-living marine bacteria: Influence of bacterioplankton upon the optical properties and particulate organic carbon in oceanic waters. J. Mar. Res. 1990, 48, 145-175. [CrossRef]

8. Babin, M.; Morel, A.; Fournier-Sicre, V.; Fell, F.; Stramski, D. Light scattering properties of marine particles in coastal and open ocean waters as related to the particle mass concentration. Limnol. Oceanogr. 2003, 48, 843-859. [CrossRef]

9. Aas, E. Refractive index of phytoplankton derived from its metabolite composition. J. Plankton Res. 1996, 18, 2223-2249. [CrossRef]

10. Verity, P.G.; Robertson, C.Y.; Tronzo, C.R.; Andrews, M.G.; Nelson, J.R.; Sieracki, M.E. Relationships between cell volume and the carbon and nitrogen content of marine photosynthetic nanoplankton. Limnol. Oceanogr. 1992, 37, 1434-1446. [CrossRef]

11. Montagnes, D.J.S.; Berges, J.A.; Harrison, P.J.; Taylor, F.J.R. Estimating carbon, nitrogen, protein, and chlorophyll $a$ from volume in marine phytoplankton. Limnol. Oceanogr. 1994, 39, 1044-1060. [CrossRef]

12. Menden-Deuer, S.; Lessard, E.J. Carbon to volume relationships for dinoflagellates, diatoms, and other protist plankton. Limnol. Oceanogr. 2000, 45, 569-579. [CrossRef]

13. Álvarez, E.; Nogueira, E.; López-Urrutia, Á. In Vivo Single-Cell Fluorescence and Size Scaling of Phytoplankton Chlorophyll Content. Appl. Environ. Microbiol. 2017, 83, e03317-16. [CrossRef] [PubMed]

14. Stramski, D.; Morel, A. Optical properties of photosynthetic picoplankton in different physiological states as affected by growth irradiance. Deep Sea Res. Part A Oceanogr. Res. Pap. 1990, 37, 245-266. [CrossRef]

15. Stramski, D.; Reynolds, R.A. Diel variations in the optical properties of a marine diatom. Limnol. Oceanogr. 1993, 38, 1347-1364. [CrossRef]

16. Stramski, D.; Shalapyonok, A.; Reynolds, R.A. Optical characterization of the oceanic unicellular cyanobacterium Synechococcus grown under a day-night cycle in natural irradiance. J. Geophys. Res. 1995, 100, 13295-13307. [CrossRef]

17. Reynolds, R.A.; Stramski, D.; Kiefer, D.A. The effect of nitrogen limitation on the absorption and scattering properties of the marine diatom Thalassiosira pseudonana. Limnol. Oceanogr. 1997, 42, 881-892. [CrossRef]

18. Durand, M.D.; Olson, R.J. Diel patterns in optical properties of the chlorophyte Nannochloris sp.: Relating individual-cell to bulk measurements. Limnol. Oceanogr. 1998, 43, 1107-1118. [CrossRef]

19. Stramski, D. Refractive index of planktonic cells as a measure of cellular carbon and chlorophyll a content. Deep Sea Res. Part I Oceanogr. Res. Pap. 1999, 46, 335-351. [CrossRef]

20. Durand, M.D.; Green, R.E.; Sosik, H.M.; Olson, R.J. Diel Variations in Optical Properties of Micromonas Pusilla (Prasinophyceae). J. Phycol. 2002, 38, 1132-1142. [CrossRef]

21. Stramski, D.; Morel, A.; Bricaud, A. Modeling the light attenuation and scattering by spherical phytoplanktonic cells: A retrieval of the bulk refractive index. Appl. Opt. 1988, 27, 3954-3956. [CrossRef] [PubMed]

22. Reynolds, R.A.; Stramski, D.; Wright, V.M.; Woźniak, S.B. Measurements and characterization of particle size distributions in coastal waters. J. Geophys. Res. 2010, 115. [CrossRef] 
23. Davies, E.J.; McKee, D.; Bowers, D.; Graham, G.W.; Nimmo-Smith, W.A.M. Optically significant particle sizes in seawater. Appl. Opt. 2014, 53, 1067. [CrossRef] [PubMed]

24. Bader, H. The hyperbolic distribution of particle sizes. J. Geophys. Res. 1970, 75, 2822-2830. [CrossRef]

25. Sheldon, R.W.; Prakash, A.; Sutcliffe, W.H., Jr. The size distribution of particles in the ocean. Limnol. Oceanogr. 1972, 17, 327-340. [CrossRef]

26. Junge, C.E. Air Chemistry and Radioactivity; Academic Press: New York, NY, USA, 1963; ISBN-13 9780123921505.

27. Stramski, D.; Kiefer, D.A. Light scattering by microorganisms in the open ocean. Prog. Oceanogr. 1991, 28, 343-383. [CrossRef]

28. Ulloa, O.; Sathyendranath, S.; Platt, T. Effect of the particle-size distribution on the backscattering ratio in seawater. Appl. Opt. 1994, 33, 7070. [CrossRef] [PubMed]

29. Röttgers, R.; Heymann, K.; Krasemann, H. Suspended matter concentrations in coastal waters: Methodological improvements to quantify individual measurement uncertainty. Estuar. Coast. Shelf Sci. 2014, 151, 148-155. [CrossRef]

30. Zapata, M.; Rodríguez, F.; Garrido, J.L. Separation of chlorophylls and carotenoids from marine phytoplankton: A new HPLC method using a reversed phase C8 column and pyridine-containing mobile phases. Mar. Ecol. Prog. Ser. 2000, 195, 29-45. [CrossRef]

31. Risović, D. Two-component model of sea particle size distribution. Deep Sea Res. Part I Oceanogr. Res. Pap. 1993, 40, 1459-1473. [CrossRef]

32. Twardowski, M.S.; Boss, E.; Macdonald, J.B.; Pegau, W.S.; Barnard, A.H.; Zaneveld, J.R.V. A model for estimating bulk refractive index from the optical backscattering ratio and the implications for understanding particle composition in case I and case II waters. J. Geophys. Res. 2001, 106, 14129-14142. [CrossRef]

33. Khelifa, A.; Hill, P.S. Models for effective density and settling velocity of flocs. J. Hydraul. Res. 2006, 44, 390-401. [CrossRef]

34. Morel, A.; Bricaud, A. Theoretical results concerning light absorption in a discrete medium, and application to specific absorption by phytoplankton. Deep Sea Res. Part A Oceanogr. Res. Pap. 1981, 28, 1375-1393. [CrossRef]

35. Marañón, E.; Cermeño, P.; Rodríguez, J.; Zubkov, M.V.; Harris, R.P. Scaling of phytoplankton photosynthesis and cell size in the ocean. Limnol. Oceanogr. 2007, 52, 2190-2198. [CrossRef]

36. Stramski, D.; Bricaud, A.; Morel, A. Modeling the inherent optical properties of the ocean based on the detailed composition of the planktonic community. Appl. Opt. 2001, 40, 2929-2945. [CrossRef] [PubMed]

37. Finkel, Z.V.; Irwin, A.J.; Schofield, O. Resource limitation alters the $3 / 4$ size scaling of metabolic rates in phytoplankton. Mar. Ecol. Prog. Ser. 2004, 273, 269-279. [CrossRef]

38. Mei, Z.P.; Finkel, Z.V.; Irwin, A.J. Light and nutrient availability affect the size-scaling of growth in phytoplankton. J. Theor. Biol. 2009, 259, 582-588. [CrossRef] [PubMed] 